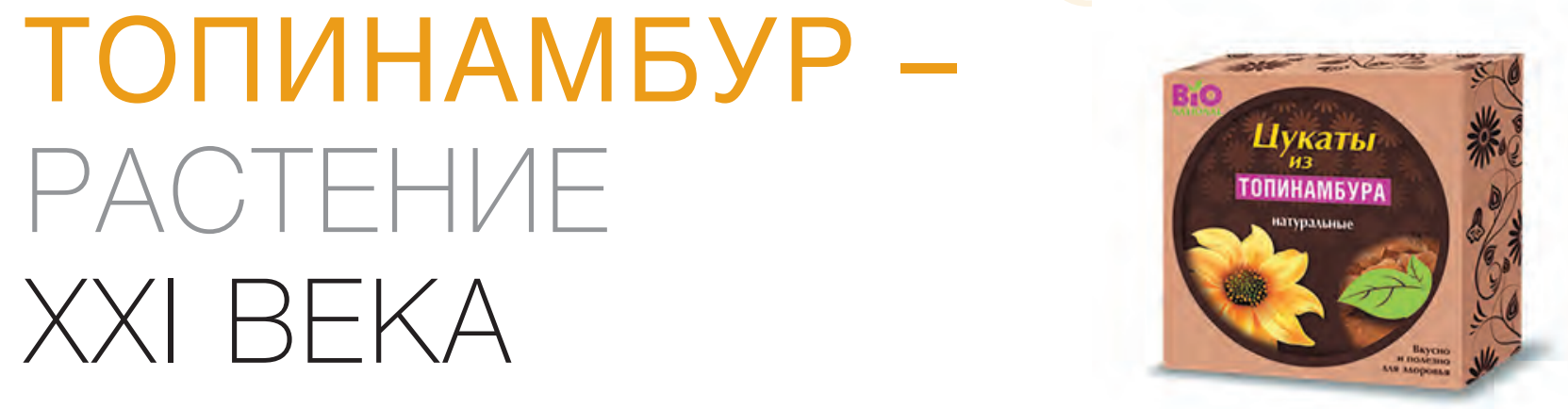

\title{
JERUSALEM ARTICHOKE IS A PLANT OF 21ST CENTURY
}

\author{
Жучкова М.А. - главный технолог \\ Скрипников С.Г. - руководитель проекта \\ О०О "Инновационный Аграрно-Промышленный Парк "КиТ" \\ 249846, Россия, Калужская обл, Дзержинский р-н \\ д.Кожухово, ул. Центральная, д.1Б \\ E-mail: info@adc-b.ru
}

В современном представлении о здоровом питании особая роль принадлежит продуктам функционального назначения, нейтрализующим неблагоприятное воздействие окружающей среды и несбалансированного питания. Перспективным сырьем для производства пребиотического и диетического питания является топинамбур. Благодаря повышенному содержанию различных биологически активных компонентов (полифенолов, витаминов, пектиновых и минеральных веществ) топинамбур признан ценным продуктом питания человека. Среди других корнеплодов его выделяет, прежде всего, высокое содержание инулина, который считается эффективным средством при лечении сахарного диабета, атеросклероза, ожирения и различных интоксикаций. 29 октября 2013 года Совет Министров Союзного государства России и Беларуси принял Программу «Инновационное развитие производства картофеля и топинамбура». Программа направлена на создание новых высокопродуктивных сортов, развития современных технологий выращивания и переработки этих культур, используя уникальный биологический потенциал топинамбура - большое содержание инулина, пектина и олигосахаридов в клубнях и зеленой массе. В Калужской области в рамках реализации Программы идет строительство Инновационного Аграрно-Промышленного Парка «Кит» по выращиванию и переработке клубней и зеленой массы топинамбура в инулин, ФОС и ФГС, диетическое и пребиотическое пюре и сокосодержащие напитки по технологии, позволяющей максимально сохранить биологически активные компоненты топинамбура. Это даст возможность производить ценные биологически активные продукты и ингредиенты, «живое» пюре и соки.

Ключевые слова: топинамбур, диетическое питание, инулин, переработка
Zhuchkova M.A., Skripnikova S.G.

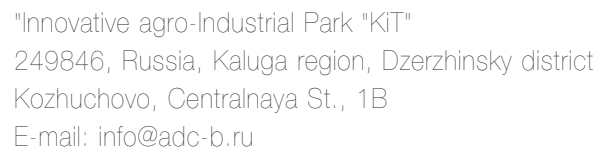

\section{Summary}

In modern concept of healthy food the products of functional destination play a main role to neutralize the influences of unfavorable environments and unbalanced diet. The Jerusalem artichoke is a promising raw material to produce prebiotic and dietary food. Owing to increased content of biologically active substances (polyphenols, vitamins, pectin and mineral compounds) the Jerusalem artichoke is recognized as valuable product for human's diet. Among other root-tuber vegetables the Jerusalem artichoke is distinguished by its high content of inulin that is regarded as an effective remedy to treat diabetes, atherosclerosis, obesity and different intoxications. On October 29, Ministry Council of Union State of Russia and Belarus accepted a program 'Innovation and Improvement of Production in Potato and Jerusalem Artichoke' aimed to develop high-yielding varieties and up-to-dated technology for production and post-harvesting processing, regarding to the biological features, namely the high contents of inulin, pectin, oligosaccharides in tubers and foliage. In Kaluga oblast, in the frame of program realization, an Innovative Agro-industrial Complex, 'KiT' is now under construction, where Jerusalem artichoke tubers and foliage are processed into inulin, fructose-oligosaccharides, fructose-glucose syrup, dietary and prebiotic puree, juice-contented drinks according to technology standards enable to preserve all valuable biologically active components. It allows manufacturing valuable biologically active products and ingredients, such as 'live' puree and juices.

Keywords: Jerusalem artichoke, dietary food, inulin, processing $\ll$ - опинамбур - растение будущего» - такое определение дал этому растению академик Николай Иванович Вавилов.

Родина земляной груши, или подсолнечника клубненосного - как в России еще называют это неприхотливое растение, или иерусалимского артишока - как его величают в англоговорящем мире, - Северная Америка, где растение растёт в диком виде, и где было введено в культуру индейцами задол- го до появления там европейцев. Первыми из европейских стран с этим овощем в 1610 году познакомилась Англия, затем Франция, где земляная груша и получила название «топинамбур» (от названия племени бразильских индейцев: тупинамба). Земляная груша оказалась настолько плодовитой, что через 20 лет после своего появления она по доступным ценам продавалась на рынках Англии. В Голландии и Бельгии топинамбур отваривали в вине со сливочным маслом, добива- 

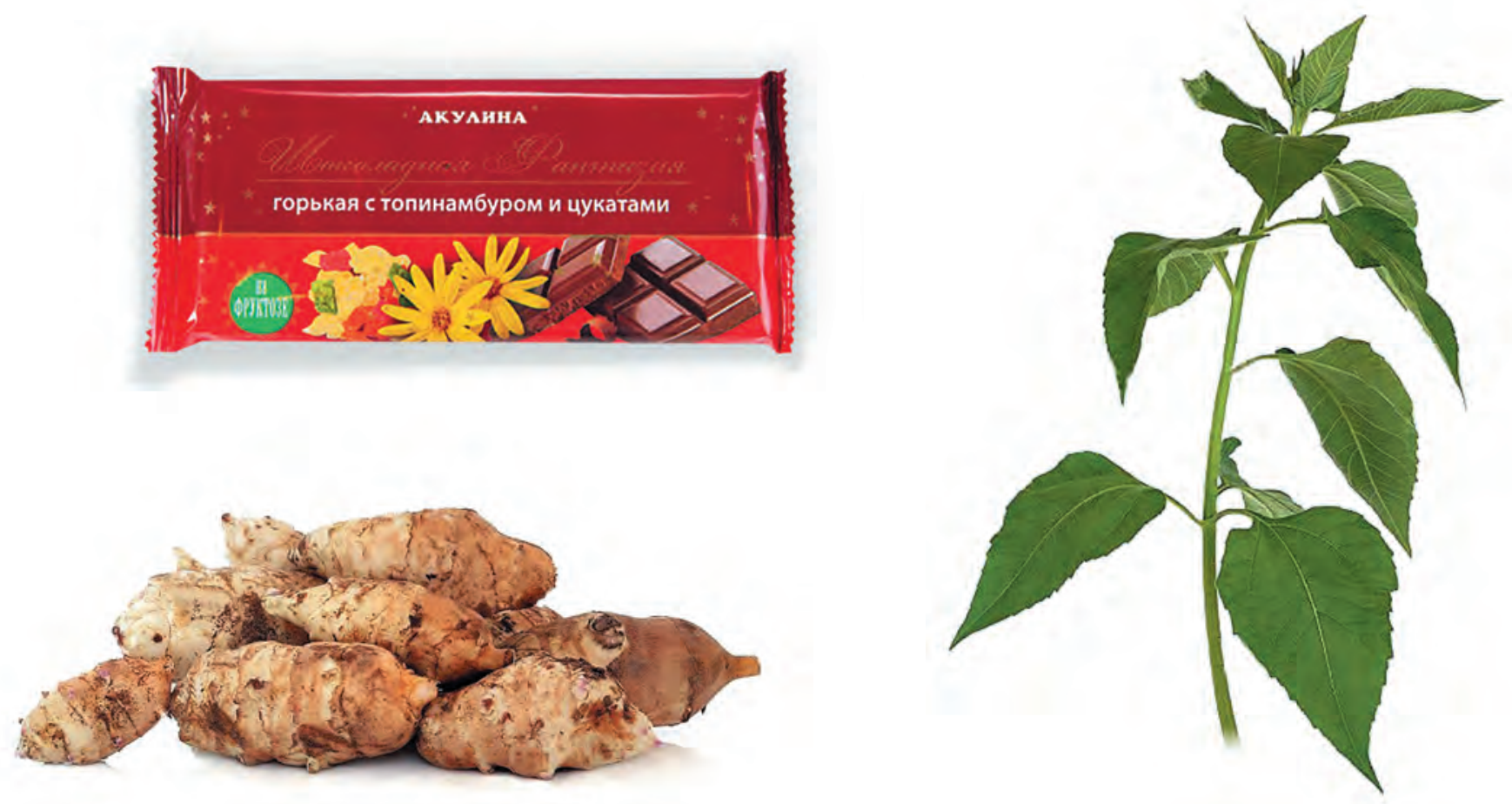

ясь сходства с донышком артишока. В Бельгии он даже назывался «подземным артишоком».

Из истории появления и культивирования этого растения в России известны следующие факты. В 1921 году по заданию Совета труда и обороны Н.И. Вавилов завез из Америки топинамбур, который должен был стать вторым хлебом и решить проблему продовольствия в СССР. Вавилов развернул активную деятельность по изучению и распространению в сельском хозяйстве этой необычной культуры, так как был поражен тем фактором, что индейцы, загнанные в резервации в глиняных пустынях, где кроме топинамбура не росли никакие другие культуры, были здоровы, физически развиты и имели многочисленное потомство. Причем у топинамбура «В дело» идут как «вершки», так и «корешки». Достаточно сказать, что зеленая вегетативная масса топинамбура («вершки») по содержанию сахаридов превосходит сахарный тростник, а клубни не имеют равных в природе по содержанию полисахаридов, и особенно ценного из них - инулина: природного заменителя инсулина. Ну а его ярко-желтые медоносные цветы украшают палисадники миллионов дачников. В 1933 году состоялась Первая Всесоюзная конференция по подсолнечнику клубненосному. А в 1937 году Наркоматом по земледелию было принято постановление об обязательном выращивании колхозами топинамбура. К сожалению, план накормить Россию топинамбуром не удался. Вскоре Н.И. Вавилов был репрессирован и проект потихоньку закрыли.

В наше время задача распространения топинамбура имеет другую цель. С развитием медицины увеличилась продолжительность жизни, но с другой стороны, ученые отмечают относительное ухудшение здоровья людей пожилого возраста, особенно живущих в крупных мегаполисах. В последние 10-20 лет отмечается рост заболеваемости сахарным диабетом во всех странах мира. В России не менее 3-5\% населения больны диабетом и до 15\% имеют симптомы этого заболевания, в том числе до 6-8\% составляют дети в возрасте до 14 лет.
Ежегодный прирост числа детей, больных инсулинозависимым диабетом, составляет 6\%. Причины этого кроются как в общем ухудшении экологической обстановки в современных мегаполисах, так и в малоподвижном образе жизни горожан, неправильном и несбалансированном питании и, как следствие, в избыточном весе со всем шлейфом негативных последствий для здоровья человека.

Для решения этих проблем 29 октября 2013 года Совет Министров Союзного государства России и Беларуси принял Программу «Инновационное развитие производства картофеля и топинамбура». Программа направлена на создание новых высокопродуктивных сортов, развития современных технологий выращивания и переработки этих культур, используя уникальный биологический потенциал топинамбура - большое содержание инулина, пектина и олигосахаридов в клубнях и зеленой массе.

В современном представлении о здоровом питании особая роль принадлежит продуктам функционального назначения, нейтрализующим неблагоприятное воздействие окружающей среды и несбалансированного питания. Очень перспективным сырьем для производства пребиотического и диетического питания является топинамбур. Благодаря повышенному содержанию различных биологически активных компонентов (полифенолов, витаминов, пектиновых и минеральных веществ) топинамбур признан ценным продуктом питания человека. Среди других корнеплодов его выделяет, прежде всего, высокое содержание инулина. Инулин, являясь резервным полисахаридом, составляет до 75\% углеводного комплекса топинамбура. Он считается эффективным средством при лечении сахарного диабета, атеросклероза, ожирения и различных интоксикаций. Установлено также, что инулин и его производные обладают комплексообразующими свойствами, что делает топинамбур ценным сырьем в производстве продуктов питания лечебно-профилактического характера. 


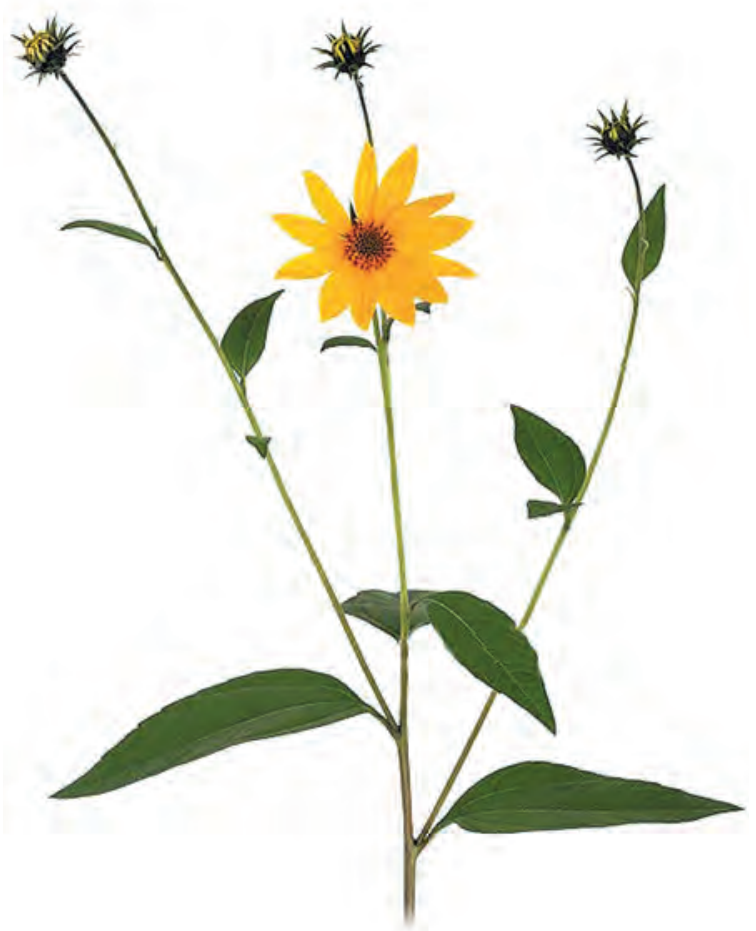

Низкомолекулярный инулин и олигосахариды используется во всем мире как заменитель сахарозы и глюкозы для диабетиков. Высокомолекулярный инулин широко используется как эмульгатор, диспергатор и гелеобразователь в различных отраслях пищевой промышленности: в хлебопечении и кондитерской промышленности, при производстве мясных и молочных продуктов. Широкое применение получили инулин и ФОС (фруктоолигосахариды) в молочных продуктах, особенно в йогуртах и кисломолочных продуктах с бифидобактериями, так как инулин и ФОС не расщепляются в кишечнике человека, а, в основном, служат пищей для «здоровых» бифидобактерий в толстой кишке, восстанавливающих нормальный обмен веществ и способствующих сбалансированному усвоению пищи человеком. В последнее время налаживается выпуск косметических средств на основе инулина.

У российских и мировых производителей пищевых продуктов большим спросом пользуется фруктозо-глюкозный сироп (ФГС), способный заменить использование сахарозы в пищевых продуктах. Диетологи многих стран мира ополчились на сахарозу как источник многих проблем, негативно сказывающихся на здоровье человека, в первую очередь, способствующих ожирению и развитию сахарного диабета. Получение фруктозо-глюкозного сиропа (ФГС) из топинамбура позволит частично решить проблему дефицита натуральных сахарозаменителей и расширить ассортимент продуктов с пониженной калорийностью для детского, диабетического и диетического питания, плодовоовощных и молочных консервов, хлеба, кондитерских изделий и напитков.

Производство ФГС тесно связано с получением инулина и фруктоолигосахаридов. В связи с этим оптимальной технологией является комплексная переработка клубней и зеленой массы топинамбура как инулиносодержащего сырья с выработкой различных функциональных продуктов: инулина, ФОС, ФГС и кормов из зеленой массы по безотходной технологии.

В 2016-2017 годах в Калужской области в рамках реа-

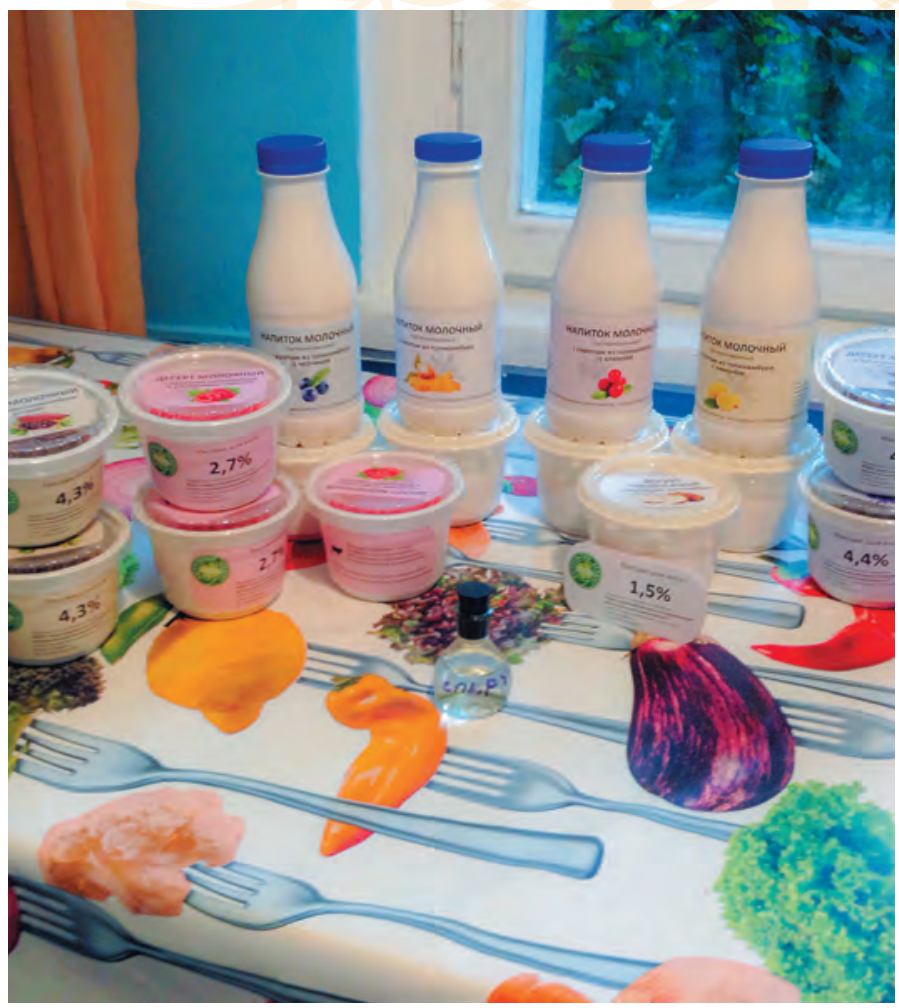

лизации Программы союзного государства «Инновационное развитие производства картофеля и топинамбура» идет строительство Инновационного Аграрно-Промышленного Парка «КиТ» по выращиванию и переработке клубней и зеленой массы топинамбура в инулин, ФОС и ФГС, диетическое и пребиотическое пюре и сокосодержащие напитки по технологии, позволяющей максимально сохранить биологически активные компоненты топинамбура. Это даст возможность производить ценные биологически активные продукты и ингредиенты, “живое» пюре и соки, что не только сократит зависимость России от импорта пищевых ингредиентов и, более того, будет иметь значительный экспортный потенциал, но и приведет к появлению на столе россиян продуктов «здорового» питания.

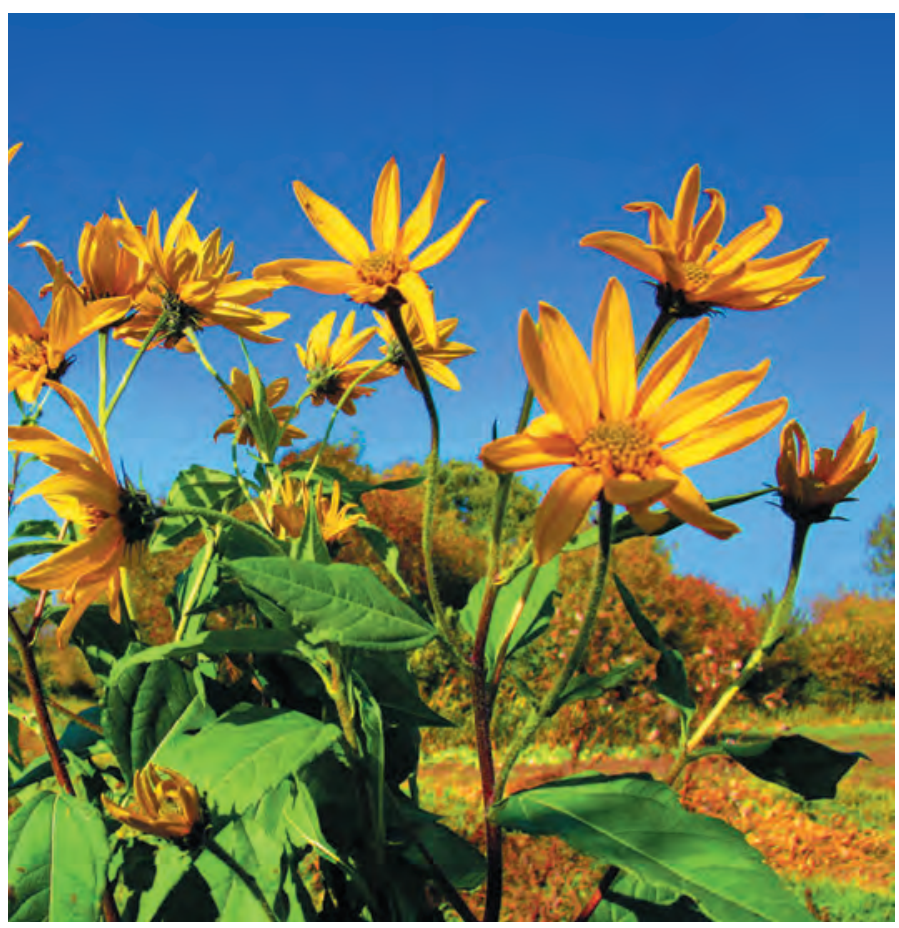

